\title{
ACCOUNTING FOR FOREIGN TRADE TRANSACTIONS: TAS-2 INVENTORIES, TAS-21 EFFECTS OF FOREIGN CURRENCY CHANGES AND A COMPARISON TO THE TURKISH TAX LAW
}

DOI: 10.17261/Pressacademia.2020.1254

PAP- V.11-2020(26)-p.132-137

Emine Yilmaz ${ }^{1}$, Suat Teker $^{2}$

${ }^{1}$ Isik University, School of Business, Istanbul, Turkey. emineemel1@gmail.com, ORCID: 0000-0003-4795-8542

2 Isik University, School of Business, Istanbul, Turkey. suat.teker@isikun.edu.tr, ORCID: 0000-0002-7981-3121

To cite this document

Yilmaz, E., Teker, S., (2020). Accounting for foreign trade transactions: TAS-2 inventories, TAS-21 effects of foreign currency changes and a comparison to the Turkish Tax Law. PressAcademia Procedia (PAP), V.11, p.132-137

Permanent link to this document: $\underline{\text { http://doi.org/10.17261/Pressacademia.2020.1254 }}$

Copyright: Published by PressAcademia and limited licensed re-use rights only.

\begin{abstract}
Purpose- With goods, services and capital movements exceed national borders, enterprises, which are parties to international trade transactions, have become in need of a common language in the field of accounting and finance in order to provide comprehensible, comparable and fair reporting. For this reason, financial statements need to be reported according to globally known accounting standards in order for individuals reading various financial information to attain the same result. The tax payable at the end of the reporting period needs to be calculated based on the taxation laws, but the accounting records thus prepared are not in concert with the standards. Differences in practices and their results constitute the subject for this papers.

Methodology- Accounting records of the products which were imported by this foreign trade company were examined and compared with TAS.

Findings- Foreign exchange differences arise in favor of or against the enterprise in the event that there is a difference between the transaction date and payment date for foreign trade transactions made in foreign currencies.

Conclusion- The principles applied in the accounting of for eign exchange differences have affected the value of the inventories, profit for the period and amount of tax to be paid at the end of the period.
\end{abstract}

Keywords: Accounting for foreign trade, Turkish Accounting Standards (TAS), Turkish Tax Law, exchange rates cahanges, cost of inventory. JEL Codes: M40, M41, M48

\section{DIŞ TICARET IŞLEMLERININ MUHASEBELEŞTiRILMESi: TMS-2 STOKLAR, TMS-21 KUR DEĞişiMININ ETKILERI STANDARTLARI ve VUK ile KARŞILAŞTIRILMASI}

\section{ÖZET}

Amaç- Mal, hizmet ve sermaye hareketlerinin ulusal sınırları aşmasıyla birlikte uluslararası ticaret işlemlerine taraf olan işletme ler; anlaşılır, karşılaştırılabilir ve gerçeğe uygun raporlama yapılabilmesi için muhasebe ve finans alanında ortak bir dile ihtiyaç duymuşlardır. Bu nedenle farklı finansal bilgi okuyucularının aynı sonuca varabilmeleri için mali tabloların uluslararası genel kabul görmüş muhasebe standartlarına göre raporlanması gerekmektedir. Raporlama dönemi sonunda ödenecek verginin, vergi kanunlarına göre hesaplanması gerekmekte fakat buna göre oluşturulan muhasebe kayıtları, standartlar ile örtüşmemektedir. Uygulama farklılıkları ve sonuçları bu çalışmanın konusunu oluşturmaktadır.

Yöntem- Bir dış ticaret işletmesinin ithal ettiği mallar ile ilgili muhasebe kayıtları incelenmiştir.

Bulgular- Yabancı para cinsinden gerçekleştirilen dış ticaret işlemlerinin, işlem tarihi ile ödeme tarihinin farklı olması halinde, işletmenin lehine ya da aleyhine kur farkları oluşmaktadır.

Sonuç- Kur farklarının muhasebeleştirilmesinde uygulanan kurallar, dönem sonunda stokların değerini, dönem kârını ve ödenecek vergi tutarını değiştirmiştir.

Anahtar Kelimeler: Dış ticaret muhasebesi, Türkiye Muhasebe Standartları, Vergi Usul Kanunu, kur farkları, stok maliyetleri. JEL Kodları: M40, M41, M48 


\section{GíRiş}

Gelişen teknoloji, ulaşım maliyetlerinin önemli oranda azalması ve ülkeler arasında ticaretin liberalleşmesi sonucunda dış ticaret hacmi artmıştır. Bu artış, kişiler ve işletmeler için sınır ötesi ürün, hizmet, sermaye, teknoloji ve bilgiye erişimin yanı sıra potansiyel yatırım fırsatları da doğurmuştur. İşletmelerin, faaliyetlerinin sonuçlarını ve finansal durumlarını genel kabul görmüş ortak bir dile göre anla şılır ve tutarlı bir şekilde raporlayabilmeleri, mevcut veya potansiyel müşteriler ile yapılan sözleşmeleri artıracaktır. Fakat her ülkenin ulusal muhasebe ilke ve kurallarına göre hazırlanmış olan tablolarını karşılaştırma zorluğu, tutarlılığının ve gerekli açıklamalarının yetersizliği nedeniyle uluslararası genel kabul görmüş bir standartlar dizisine ihtiyaç duyulmuştur. UFRS kullanımındaki ana fikir, raporlama birimleri tarafından tutarlı bir çerçevede ve ihtiyaçlar doğrultusunda hazırlanan finansal tabloların herhangi bir düzenlemeye gerek duyulmadan kolayca karşılaştırılabilmesidir.

Bu çalışmanın amacı, vergi kanunlarına göre muhasebeleştirilen ithalat işlemlerinin ve TMS'ye göre kaydedilmesi halinde oluşa cak farkları incelenmesidir. Türkiye'de muhasebe uygulamaları, vergi mevzuatının etkisi altında olduğundan uluslararası ekonomik çevrelerde faaliyet gösteren işletmeler için birden fazla finansal tablo hazırlama gerekliliği bulunmaktadır. Çalışmanın kapsamını, İstanbul'da elektronik komponent ithalatı yapan bir dış ticaret firmasının ithal ettiği ticari mallar ile ilgili muhasebe kayıtları oluşturmaktadır. Bu firmanın VUK'a göre oluşturulan muhasebe kayıtları ve finansal tabloları TMS-2 Stoklar Standardı ve TMS-21 Kur Değişiminin Etkileri Standardı kapsamında karşılaştırılmıştır. Uluslararası muhasebe standartları hakkında literatür taraması yapılmış ve bu konularda yayımlanan makale, dergi, kitap, tez çalışmalarının yanı sıra ilgili kurum ve kuruluşların internet ortamındaki yayınlarından faydalanılmıştır. Çalışma, ithalat işlemleri ile sınırlandırılarak işletmenin faaliyet sonuçlarını ve finansal durum raporlarını etkileyen stoklar ve kur farklarının, vergikanu nlarıve standartlara göre muhasebeleştirilmesi sonucu oluşan farklılıklar ve benzerlikler ele alınmıştır.

\section{ULUSLARARASIMUHASEBE STANDARTLARI}

\subsection{TMS-2 Stoklar Standardi}

TMS-2 Stoklar Standardı, stok maliyetinin belirlenmesine ve sonrasında gider olarak finansal tablolara alınmasına ilişkin (stokun net gerçekleşebilir değere indirgenmesi de dâhil) bilgi sağlar. Bu Standart ayrıca maliyetlerin stoklara yüklenmesinde kullanılan maliyet hesaplama yöntemleri hakkında bilgi sağlar (TMS 2, P.1).

Stokların maliyeti; satın alma sürecinde katlanılan maliyetleri, bir ürünün üretilmesi veya inşa edilebilmesi için katlanılan maliyetleri ve stokların satışa ya da kullanıma hazır hale getirilebilmesi için katlanın tüm maliyetleri ifade eder (TMS 2, P.10).

Özellikli bir varlığın elde edilmesi, inşa edilmesi veya üretilmesi ile doğrudan ilişkilendirilebilen borçlanma maliyetleri, varlığın maliyetine ilave edilmelidir (TMS 23, P.8). Kullanıma hazır hale gelmeleri uzun zaman alan köprü, elektrik santrali ve barajlar, inşası uzun süre gerektiren varlıklar, özellikli varlıklar olarak sınıflandırılabilir. Edinildiklerinde, satışa veya kullanıma hazır olan varlıklar bu standart kapsamında özellikli varlık değildir (Mirza, 2011). TMS-23 Borçlanma Maliyetleri Standardına göre bir stok özellikli varlık sınıfına girmiyor ve vadeli alımı ile peşin alımı arasında fark bulunuyorsa bu fark stok maliyetine dâhil edilemez. Dönem giderleri arasında finansal tablolara alınmalıdır.

Satılan stokların kayıtlı değeri, bu stokların satışının gerçekleştiği dönemde gider olarak kaydedilir. Stokların net gerçekleşebilir değerinin maliyet değerinden düşük olması halinde stoklar net gerçekleşebilir değerinden değerlenir. Net gerçekleşebilir değer ile kayıtlı değer arasındaki fark ise stok değer düşüklüğü karşılığı olarak kaydedilir. Bir sonraki dönemde net gerçekleşebilir değerin artması durumunda, iptal edilmesi gereken tutar ilgili dönemin satış maliyetini azaltmak suretiyle muhasebeleştirilir (TMS 2, P.34).

Maliyetesasına göre muhasebeleştirilen varlıklarınzamaniçinde değerlerinde değişiklik olabilmekte vekayıtlı değeriile piyasa değeriarasında önemli farklar oluşabilmektedir. Finansal tablo kullanıcılarının doğru kararlar alabilmesi için varlık ve kaynakların gerçeğe uygun değerlenmesi gerekir. Gerçeğe uygun bir sunum ise muhasebe kayıt ve değerleme esaslarının güvenilirliği ve doğruluğu ile mümkündür. (Tunçez, 2019)

Net gerçekleşebilir değer, bir malın tahmini satış fiyatından tahmini tamamlanma maliyetlerinin ve satış giderlerinin indirilmesi sonucunda ortaya çıkan değeri ifade eder. Gerçeğe uygun değer ise, söz konusu malın herhangi bir pazar ortamında takas edilebileceği de ğerdir. Net gerçekleşebilir değer, işletme sınırları içerisinde tespit edilebilirken gerçeğe uygun değer işletme dışında oluşmaktadır (TMS 2, P.7).

Stoklar ile ilgili işlemlerin VUK ve TMS yönünden benzerlikleri ve farklılıkları aşağıda ki Tablo 1'de özetlenmiştir.

Tablo 1: Mal Stokları ile İ igili Standartalrın TMS ve VUK Arasında Karşılaştırılması

\begin{tabular}{|l|l|l|}
\hline & TMS & VUK \\
\hline $\begin{array}{l}\text { Stokların Satın Alma } \\
\text { Maliyeti }\end{array}$ & $\begin{array}{l}\text { Stokların elde edilmesi ile ilgili katlanılan nakliye, } \\
\text { yükleme, boşaltma, depolama, sigorta, montaj, } \\
\text { gümrük vergileri ve vergi idaresinden iadesi } \\
\text { alınamayacak tüm vergiler stokların satın alma } \\
\text { maliyetini oluşturur. }\end{array}$ & TMS ile uyumludur. \\
\hline $\begin{array}{l}\text { Stokların Dönüştürme } \\
\text { Maliyetleri }\end{array}$ & $\begin{array}{l}\text { Normal maliyet yöntemi uygulanır, âtıl kapasite } \\
\text { payına düşen sabit giderler, dönem gideri olarak } \\
\text { muhasebeleştirilir. }\end{array}$ & $\begin{array}{l}\text { Tam maliyet yöntemi uygulanır, âtıl kapasite payına } \\
\text { yüklenir. }\end{array}$ \\
\hline Stokların Diğer Maliyetleri de üretilen malın maliyetine & $\begin{array}{l}\text { Malın özellikli bir varlık olmaması halinde peşin } \\
\text { fiyatı ile vadeli fiyatı arasında fark, dönemin } \\
\text { finansman gideri olarak muhasebeleştirilir. }\end{array}$ & $\begin{array}{l}\text { Malın peşin fiyatı ile vadeli fiyatı arasında fark ve } \\
\text { olumsuz kur farkları, satın alınan malın maliyetine ilave } \\
\text { edilir. }\end{array}$ \\
\hline
\end{tabular}




\begin{tabular}{|l|l|l|}
\hline $\begin{array}{l}\text { Hizmet Sunan } \\
\text { işletmelerde Stok Maliyeti }\end{array}$ & $\begin{array}{l}\text { Hasılatı henüz gelir tablosuna kaydedilmemiş } \\
\text { hizmetlere ait giderler raporlama dönemi sonunda } \\
\text { stoklar arasına alınır. }\end{array}$ & $\begin{array}{l}\text { Raporlama dönemi boyunca tüm hizmetler gider olarak } \\
\text { muhasebeleştirilir, dönem sonunda hizmete ait gelirin } \\
\text { elde edilip edilmediğine bakılmaksızın gelir tablosu } \\
\text { hesaplarına aktarılır. }\end{array}$ \\
\hline $\begin{array}{l}\text { Stok Maliyetlerini } \\
\text { Hesaplama Yöntemleri }\end{array}$ & $\begin{array}{l}\text { Gerçek Parti Maliyet Yöntemi, FIFO (illk Giren, Illk } \\
\text { Çıkar), Ağırlıklı Ortalama Maliyet Yöntemi }\end{array}$ & TMS ile uyumludur. \\
\hline $\begin{array}{l}\text { Stoklarda } \\
\text { Değer Düşüklüğü }\end{array}$ & $\begin{array}{l}\text { Stoklar net gerçekleşebilir değer ve maliyet } \\
\text { değerinden düşük olanıyla değerlenir. Değer } \\
\text { düşüklüğü için karşılık ayrılır. }\end{array}$ & $\begin{array}{l}\text { Stokların satış fiyatının, maliyet bedelinin \%10 altına } \\
\text { inmesi halinde karşlık ayrılır }\end{array}$ \\
\hline
\end{tabular}

\subsection{TMS-21 Kur Değişiminin Etkileri Standardı}

Bir işletmenin dövizli işlemlere taraf olma nedenleri şöyle sıralanabilir (PKF International Ltd, 2018):

- Döviz cinsinden fiyatlanmış mal veya hizmetin, alınıyor veya satılıyor olması,

- Borç alma veya borç verme halinde, alacak veya borç tutarlarının döviz üzerinden ifade edilmesi,

- Yabancı para ile ifade edilen bir sözleşmeye taraf olunması,

- Bunların dışındaki nedenlerle varlık satın alınması veya elden çıkarılması ya da döviz cinsinden borçlara katlanılması veya y erine getirilmesi.

Dünya genelinde dış ticaret işlemlerinin artması, farklı para birimleri ile yapılan işlemlerin muhasebeleştirilmesi ve finansal tabloların yabancı para birimine çevrilmesi; TMS-21 Kur Değişiminin Etkileri Standardında belirlenen ilke ve kurallara göre yapılmalıdır. İşletmelerin geçerli para biriminden farklı para birimleri ile faaliyet göstermesi halinde bu standardın diğer standartlarla birlikte dikkate alınması ve finansal tablolara etkilerinin birlikte değerlendirilmesi gerekmektedir. Örneğin, varlık satın alımı ile ilgili bedelin yabancı para ile ödenmesi ve geçerli para birimine göre muhasebeleştirilmesi sonucu raporlama dönemi sonunda olumlu ya da olumsuz kur farkları oluşabilmekte ve bu farkların bilançoda mı yoksa gelir tablosunda mı raporlanacağı önem arz etmektedir.

Bir yabancı para işlemi ilk muhasebeleştirme sırasında; yabancı para birimindeki tutara, geçerli para birimi ile işlem tarihindeki yabancı para birimi arasındaki geçerli kur uygulanarak, geçerli para biriminden kaydedilir (TMS 21, P.21). Türkiye Finansal Raporlama Standartları'na göre işlemin ilk kaydının oluşturulması gerektiği tarihi ifade eden işlem tarihinde, gerçek kura yakın bir kur seçilebilir. Döviz kurunun önemli ölçüde dalgalanmadığı dönemlerde haftanın ya da ayın ortalama kurunun o dönemin tüm işlemlerinde kullanılması mümkündür.

Her raporlama dönemi sonunda yabancı paralı işlemlerin raporlamasında göz önünde bulundurulacak hususlar şöyledir (TMS 21, P.23):

- Parasal kalem olarak yabancı para cinsinden ifade edilen varlık ya da yükümlülükler kapanış kurundan,

- Tarihi maliyetiyle ölçülmesi gereken yabancı para cinsinden parasal olmayan kalemler, işlem tarihindeki döviz kurundan,

- Gerçeğe uygun değeriyle ölçülmesi gereken yabancı para cinsinden parasal olmayan kalemler, ölçümün yapıldığı tarihte ki döviz kurundan çevrilir.

Parasal kalemlerin ödenmesinden ya da dönem içinde veya önceki dönemde ilk muhasebeleştirildikleri tarih ile çevrildikleri günün kuru arasında oluşan kur farkları dönemin kâr veya zararında muhasebeleştirilir.

Parasal olmayan kalemlerle ilgili kur farkları ilgili kalemlerin kazanç veya zararlarının raporlandığı yere göre iki şekilde muhasebeleştirilir;

- Parasal olmayan kalemin kazanç veya zararı dönemin kâr veya zararında muhasebeleştirilirse kur farkı da kâr veya zararda,

- Parasal olmayan kalemin kazanç veya zararı diğer kapsamlı gelirde muhasebeleştirilirse kur farkı da diğer kapsamlı gelir tablosunda muhasebeleştirilir.

Kur Değişimi ile ilgili işlemlerin VUK ve TMS yönünden benzerlikleri ve farklılıkları aşağıda Tablo 2' de özetlenmiştir.

Tablo 2: Mal Stokları Üzerindeki Kur Değişim Etkilerinin TMS ve VUK Açısından Karşılaştırılması

\begin{tabular}{|l|l|l|}
\hline & TMS & VUK \\
\hline Kullanılan Para Birimi & $\begin{array}{l}\text { Işletmenin içinde bulunduğu ekonomik çevrede } \\
\text { geçerli para birimidir. }\end{array}$ & TMS ile uyumludur. \\
\hline İlk Muhasebeleştirme & $\begin{array}{l}\text { Döviz kurunun önemli ölçüde dalgalanmadığı } \\
\text { dönemlerde, işlem tarihindeki gerçek kura yakın, } \\
\text { haftanın ya da ayın ortalama kuru ile } \\
\text { muhasebeleştirilir. }\end{array}$ & $\begin{array}{l}\text { Türkiye Cumhuriyet Merkez Bankası'nda } \\
\text { yayınlanan işlem tarihindeki geçerli kur ile } \\
\text { muhasebeleştirilir. }\end{array}$ \\
\hline Kur Farkları & $\begin{array}{l}\text { Elde edilen varlığın özellikli varlık olması halinde } \\
\text { varlığın maliyetinde, aksi halde dönem kâr ve } \\
\text { zarar tablosunda raporlanır. }\end{array}$ & $\begin{array}{l}\text { Varlığın özellikli olup olmadığına bakılmaksızın elde } \\
\text { edilme tarihine kadar oluşan kur farkları varlığın } \\
\text { maliyetine, elde edildikten sonra ortaya çıkan kur } \\
\text { farkları ise varlığın maliyetinde ya da gelir } \\
\text { tablosunda raporlanır. }\end{array}$ \\
\hline $\begin{array}{l}\text { Raporlama Dönemi Sonunda } \\
\text { Yabancı Parasal Kalemler }\end{array}$ & $\begin{array}{l}\text { Raporlama dönemi sonunda yabancı parasal } \\
\text { kalemler dönemin kapanış kurundan raporlanır. }\end{array}$ & $\begin{array}{l}\text { Kapanış tarihinde Türkiye Cumhuriyet Merkez } \\
\text { Bankası' nda yayınlanan geçerli kurdan raporlanır. }\end{array}$ \\
\hline $\begin{array}{l}\text { Raporlama Dönemi Sonunda } \\
\text { Tarihi Maliyet ile Öllçülen }\end{array}$ & $\begin{array}{l}\text { Işlem tarihinde gerçeğe yakın olan bir döviz } \\
\text { kurundan çevrilir. }\end{array}$ & $\begin{array}{l}\text { Şlem tarihinde Türkiye Cumhuriyet Merkez } \\
\text { Bankası'nda yayınlanan geçerli kurdan raporlanır. }\end{array}$ \\
\hline
\end{tabular}




\begin{tabular}{|l|l|l|}
\hline $\begin{array}{l}\text { Yabancı Para Cinsinden } \\
\text { Parasal Olmayan Kalemler }\end{array}$ & \\
\hline $\begin{array}{l}\text { Raporlama Dönemi Sonunda } \\
\text { Gerçeğe Uygun Değer ile } \\
\text { Ölçülen Yabancı Para } \\
\text { Cinsinden Parasal Olmayan } \\
\text { Kalemler }\end{array}$ & $\begin{array}{l}\text { Değerlemenin yapıldığı tarihte gerçeğe yakın } \\
\text { olan bir döviz kurundan çevrilir. }\end{array}$ & $\begin{array}{l}\text { Işlem tarihinde Türkiye Cumhuriyet Merkez } \\
\text { Bankası'nda yayınlanan geçerli kurdan raporlanır. }\end{array}$ \\
\hline $\begin{array}{l}\text { Finansal Tabloların Geçerli } \\
\text { Para Biriminden Farklı Bir Para } \\
\text { Birimine Çevrilmesi }\end{array}$ & $\begin{array}{l}\text { Işletmenin varlık ve yabancı kaynakları bilanço } \\
\text { tarihindeki kapanış kurundan, gelir-gider ve öz } \\
\text { kaynakları ise işlem tarihindeki kurdan çevrilir. }\end{array}$ & Herhangi bir düzenleme yoktur. \\
\hline
\end{tabular}

\section{DIŞ TiCARET işLEMLERININ MUHASEBELEŞTiRILMESi}

VUK'a ve TMS'ye göre ithal edilen malın maliyetini oluşturan unsurlar arasında bazı farklılıklar bulunmaktadır:

- Bir malın vadeli fiyatı ile peşin fiyatı arasında fark bulunması halinde vade farkına isabet eden tutar VUK'a göre malın maliyetine ilave edilirken TMS'ye göre dönemin finansman gideri olarak muhasebeleştirilmelidir.

- Peşin ithalatlarda döviz kurunun ödemenin yapıldığı tarihte yüksek olup ithalatın gerçekleştiği tarihte düşük olması halinde ithalatçı için olumsuz kur farkı oluşmaktadır. Bu kur farklarının VUK'a göre malın maliyetinde, TMS'ye göre dönem g iderleri arasında muhasebeleştirilmesi gerekir.

Örneğin, bir alıcı ve satıcı arasında yapılan sözleşmede, 920.000 adet Diyot' un peşin alış fiyatı 22.330,00 USD olup vade farkı aylık \%3'tür. İthalatçı firma 30 gün vadeli ödeme yöntemini seçerek 669,90 USD tutarındaki vade farkını ödemeyi kabul etmiştir. 13.06 .2019 tarihinde gerçekleşen ithalata ait TMS ve VUK'a göre oluşturulan karşılaştırmalı muhasebe kayıtları şöyle olacaktır.

\begin{tabular}{|c|c|c|c|c|c|}
\hline \multicolumn{3}{|c|}{ VUK } & \multicolumn{3}{|l|}{ TMS } \\
\hline$\ldots .13 .06 .2019 \ldots$ & & & $\ldots .13 .06 .2019 \ldots$ & & \\
\hline $\begin{array}{l}153 \text { Ticari Mallar } \\
\text { Diyot } 920.000 \text { adet } \\
\$ 22.330,00 * 5,8101\end{array}$ & $129.739,53$ & & $\begin{array}{l}153 \text { Ticari Mallar } \\
\text { Diyot } 920.000 \text { adet } \\
\$ 22.330,00 * 5,8101\end{array}$ & $129.739,53$ & \\
\hline $\begin{array}{l}153 \text { Ticari Mallar } \\
\text { Diyot } 920.000 \text { adet } \\
\$ 669,90 * 5,8101\end{array}$ & $3.892,18$ & & $\begin{array}{l}328 \text { Ertelenmiş Vade Farkı } \\
\text { Giderleri }\end{array}$ & $3.892,18$ & \\
\hline $\begin{array}{l}\text { 320.x Yurt Dışı Satıcılar } \\
\$ 22.999,90 * 5,8101\end{array}$ & & $133.631,71$ & $\begin{array}{l}\text { 320.x Yurt Dışı Satıcılar } \\
\$ 22.999,90 * 5,8101\end{array}$ & & $133.631,71$ \\
\hline $\begin{array}{l}\text { Vadeli alınan ticari malın } \\
\text { muhasebe kaydı }\end{array}$ & & & $\begin{array}{l}\text { Vadeli alınan ticari malın } \\
\text { muhasebe kaydı }\end{array}$ & & \\
\hline
\end{tabular}

Örneğin, bir işletme ithal edeceği rezistans için 23.07.2019 tarihinde satıcıya \$34.893,50 ödemiş olup fiili ithalat 31.07 .2019 tarihinde gerçekleşmiştir. Ödemenin ve ithalatın gerçekleştiği tarihlerdeki döviz kurları ve oluşan kur farkları şöyledir:

\begin{tabular}{|l|c|c|c|c|c|}
\hline & Tarih & MB Döviz Alıs Kuru & MB Döviz Satış Kuru & Mal Bedeli USD & Mal Bedeli TL \\
\hline Transfer & 23.07 .2019 & 5,6684 & & $34.893,50$ & $197.790,32$ \\
\hline Fiili İthalat & 31.07 .2019 & & 5,581 & $34.893,50$ & $194.740,62$ \\
\hline Fark & & & $3.049,69$ \\
\hline
\end{tabular}

Ortaya çıkan kur farklarının TMS ve VUK'a göre karşılaştırmalı muhasebe kaydı şöyle olacaktır.

\begin{tabular}{|c|c|c|c|c|c|}
\hline VUK & & & TMS & & \\
\hline$\ldots .31 .07 .2019 \ldots$ & \multirow{3}{*}{$3.049,69$} & \multirow[b]{3}{*}{$3.049,69$} & $\ldots .31 .07 .2019 \ldots$ & \multirow{3}{*}{$3.049,69$} & \multirow[b]{3}{*}{$3.049,69$} \\
\hline $\begin{array}{l}\text { 153.001.x Ticari Mallar } \\
\text { (Rezistans } 41.148 \text { adet) }\end{array}$ & & & 674 Kur Farkı Zararları & & \\
\hline $\begin{array}{l}\text { 159.001.x Verilen Sipariş Avansları } \\
\text { Kur farklarının muhasebe kaydı }\end{array}$ & & & $\begin{array}{l}\text { 159.001.x Verilen Sipariş Avansları } \\
\text { Kur farklarının muhasebe kaydı }\end{array}$ & & \\
\hline
\end{tabular}


İthal edilen ticari malın maliyetinin hesaplanmasında TMS ve VUK karşılaştırmasını şu şekilde özetlenebilir.

\begin{tabular}{|l|l|l|}
\hline & TMS & VUK \\
\hline $\begin{array}{l}\text { Peşin ithalatlarda ödeme tarihi ile ithalat tarihi } \\
\text { arasındaki olumsuz kur farkları }\end{array}$ & $\begin{array}{l}\text { Dönemin finansman giderinde } \\
\text { muhasebeleştirilir. }\end{array}$ & $\begin{array}{l}\text { İthal edilen malın maliyetinde } \\
\text { muhasebeleştirilir. }\end{array}$ \\
\hline $\begin{array}{l}\text { Peşin ithalatlarda ödeme tarihi ile ithalat tarihi } \\
\text { arasındaki olumlu kur farkları }\end{array}$ & Kur farkı gelirlerine kaydedilir. & Kur farkı gelirlerine kaydedilir. \\
\hline Vadeli ithalatlarda olumlu kur farkları & Kur farkı gelirlerine kaydedilir. & Kur farkı gelirlerine kaydedilir. \\
\hline Vadeli ithalatlarda olumsuz kur farkları & $\begin{array}{l}\text { Dönemin finansman giderinde } \\
\text { muhasebeleştirilir. }\end{array}$ & $\begin{array}{l}\text { Kambiyo zararlarında } \\
\text { muhasebeleştirilir. }\end{array}$ \\
\hline $\begin{array}{l}\text { Vadeli ithalatlarda, malın peşin fiyatı ile vadeli fiyatı } \\
\text { arasında vade farkı olması halinde }\end{array}$ & $\begin{array}{l}\text { Dönemin finansman giderinde } \\
\text { muhasebeleştirilir. }\end{array}$ & $\begin{array}{l}\text { İthal edilen malın maliyetinde } \\
\text { muhasebeleştirilir. }\end{array}$ \\
\hline
\end{tabular}

Örneğin bir işletmenin, haziran ayında oluşan ve elde kalan stokların maliyetine yüklenen vade farkı toplamı 2.998,34 TL, kur farkı toplamı 11.743,56 TL' dir. Bu farkların, stoklarınmaliyetinde değil de finansman giderlerinde muhasebeleştirmesi halinde dönemin finansman giderleri toplamı 2.626.403,73 TL olarak raporlanacak ve işletmenin vergi öncesi kâr veya zararı TMS ve VUK'a göre şöyle hesaplanacaktır:

\begin{tabular}{|l|c|c|}
\hline KAR veya ZARAR TABLOSU & $\begin{array}{c}\text { Cari Dönem 2019 } \\
\text { VUK }\end{array}$ & $\begin{array}{c}\text { Cari Dönem 2019 } \\
\text { TMS }\end{array}$ \\
\hline GELiR ve GiDER KALEMLERi & $19.842 .356,20$ & $19.842 .356,20$ \\
\hline Satış Gelirleri (net) & $-14.399 .257,99$ & $-14.399 .257,99$ \\
\hline Satışların maliyeti (-) & $\mathbf{5 . 4 4 3 . 0 9 8 , 2 1}$ & $\mathbf{5 . 4 4 3 . 0 9 8 , 2 1}$ \\
\hline BRÜT KAR/ZARAR & $-2.440 .500,26$ & $-2.440 .500,26$ \\
\hline Faaliyet Giderleri (-) & $\mathbf{3 . 0 0 2 . 5 9 7 , 9 5}$ & $\mathbf{3 . 0 0 2 . 5 9 7 , 9 5}$ \\
\hline FAALiYET KARI/ZARARI & $\mathbf{- 1 2 8 . 1 6 6 , 4 6}$ & $-128.166,46$ \\
\hline Diğer Gelir ve Giderler (net) & $\mathbf{- 2 . 6 1 1 . 6 6 1 , 8 3}$ & $\mathbf{2 . 6 2 6 . 4 0 3 , 7 3}$ \\
\hline Finansal Giderler (-) & $\mathbf{2 6 2 . 7 6 9 , 6 6}$ & $\mathbf{2 4 8 . 0 2 7 , 7 6}$ \\
\hline VERGi ÖNCESi KÂR/ZARAR & & \\
\hline
\end{tabular}

İşletmenin VUK'a göre düzenlenmiş 2019 yılı ikinci dönem gelir tablosunda, dönemin finansman gideri olarak kaydedilmesi gereken vade farkı ve kur farkı tutarları, stokların maliyetine yüklendiği için elde kalan stokların payına düşen vade farkı ve kur farkı tutarları finansman gideri toplamına dahil edilememiştir. Dönem giderlerinin hasılattan indirilememiş olması hesaplanan kârın fazla olmasına dolayısıyla kâr payı ve vergi ödemelerinin de olması gerektiğinden fazla olmasına neden olmuştur.

\section{SONUÇ}

İşletmeler vergi matrahını, vergimevzuatına göre hesaplamak zorunda oldukları için uluslararasıgenel kabul görmüş muhasebe standartlarına uygun mali tablo hazırlamak isteyenler, Dışardan Atılan Kayıt tekniği ile tablolarını Türkiye Finansal Raporlama Standartlarına uyumlu hale getirebilmektedirler. Bu da standartların yaygın halde kullanılmasının önünde aşılması zor bir engel teşkil etmektedir.

Döviz kurunun yüksek olduğu dönemde peşin ödemesi yapılan malın, döviz kurunun düşük olduğu dönemde yurda getirilmesi sonucu ithalatçı için olumsuz kur farkı oluşmuştur. Bu kur farkı, VUK' a göre ithal edilen malın maliyetine dahil edilmiş, TMS' ye göre kur fa rkı zararı olarak muhasebeleştirilmiştir.

TMS-23 Borçlanma Maliyetleri Standardı, vadeli fiyat ile peşin fiyat arasındakifarkın dönemin finansman giderleriarasında raporlanmasını gerektirirken; VUK, vade farklarının stokların maliyetine dahil edilmesini zorunlu tutmuştur.

Gerçeğe uygunluktan uzak bir rapor finansal rapor, kullanıcılarını yanıltacak ve geleceğe dönük hatalı k ararlar alınmasına neden olabilecektir. Bu nedenle vergi kanunlarının, uluslararası genel kabul görmüş standartlara göre yeniden gözden geçirilmesi önerilmektedir.

\section{KAYNAKÇA}

Doğan, Ö., \& Altınkaynak, F. (2019), Turizm Şirketlerinde Hizmet Üretim Maliyetlerini Raporlama Sorunları. Business \& Management Studies, 1893.

Mirza, A. A. (2011). Wiley IFRS: Practical Implementation Guide and Workbook.

PKF International Ltd. (2018). Wiley Interpretation and Application of IFRS Standards. New Jersey: John Wiley \& Sons, Ltd.

TMS 2, TMS-2 Stoklar Standardı. 05 03, 2020 tarihinde www.kgk.gov.tr

TMS 21, TMS-21 Kur Değişiminin Etkileri Standardı. 05 02, 2020 tarihinde www.kgk.gov.tr 
TMS 23, TMS-23 Borçlanma Maliyetleri. 05 03, 2020 tarihinde www.kgk.gov.tr

Tunçez, H. A. (2019). Türkiye Muhasebe Standartları (TMS) ile Vergi Usul Kanunu (VUK) Açısından Değerleme Ölçümlerinin Karşılaştırılması. Avrasya Sosyal ve Ekonomi Araştırmaları Dergisi, 209-218. 